\title{
CAMIÑNANDO POLA LINGUA E A LITERATURA GALEGAS NA ATMOSFERA CONMEMORATIVA DO XACOBEO 2021-2022
}

A WALK THROUGH GALICIAN LANGUAGE AND LITERATURE IN THE COMMEMORATIVE ATMOSPHERE OF THE XACOBEO 2021-2022

Mailson Lopes ${ }^{1}$ Centro de Estudos da Lingua e Cultura Galegas Universidade Federal da Bahia Araceli Luna ${ }^{2}$ Centro de Estudos da Lingua e Cultura Galegas Universidade Federal da Bahia Organizadores

A experiencia do camiño, do ato de camiñar, consiste, sen dúbida, nunha das experiencias máis simples e, ao mesmo tempo, máis representativas practicadas pola humanidade. Incluso non é raro que conceptualicemos a vida ou o modus vivendi en termos de rutas, de percorridos. Proxeccións metafóricas que deixan patente a centralidade dos desprazamentos, dos movementos por traxectos, das idas e vindas polo mundo, polas vías sinuosas (e non poucas veces sorprendentes) da existencia.

1 mailson.lopes@ufba.br

2 araceli.luna.magarinos@gmail.com 
Entre todas as formas de camiñar, polos máis diferentes itinerarios posíbeis, interésanos aquí aquela que se finca na experiencia - nunca estática, nunca uniforme, sempre polifacética e instigadora - de percorrer Galicia polas sendas da súa lingua e da súa literatura. Tal recorte xustifícase plenamente polo contexto no que agora nos atopamos: o do Xacobeo 2021-2022, conmemoración da peregrinación xacobea, do ano santo compostelán, do Apóstolo Santiago; en definitiva, conmemoración de Galicia, da súa historia, da súa cultura e do seu pobo.

O Centro de Estudos da Lingua e Cultura Galegas (CELGA), núcleo académico-universitario oficial de promoción da galeguidade na Bahia, non podería quedar fóra deste percorrido conmemorativo, pois o transitar polos campos de interese atinentes a Galicia integra a súa esencia mesma. Este aspecto deixase entrever no propio escudo do CELGA, no cal vemos un decidido peregrino, que porta unha capa na que se debuxan a lúa e as estrelas, que se pon a camiñar, orientado pola rosa dos ventos. Unha imaxe que representa boa parte do que vén facendo este centro de estudos galegos desde 1995, ano da súa fundación: un continuo camiñar en dirección a Galicia e, a partir dela, un fluxo de retorno ao Brasil, nun perenne e frutífero traxecto bidireccional entre os dous lados do Atlántico.

Por motivo do xacobeo compostelán e tamén no clima do xubileu de prata da fundación do CELGA, a coordinación e o lectorado deste centro de estudos galegos situado na Universidade Federal da Bahia (UFBA) trazaron as primeiras liñas dunha proposta de publicación dedicada á lingua e á literatura galegas que puidese vir á luz como un marco festivo e duradeiro destas tan importantes e significativas conmemoracións. Estabelecemos, para este fin, unha colaboración cos editores da revista Estudos Linguísticos e Literários, do Instituto de Letras da UFBA, e, pouco tempo despois, após seren remitidos os convites a eminentes investigadores dos estudos galegos e despois de ser lanzada a convocatoria pública, xa tínamos entre as mans case unha trintena de artigos. Após coidadosa 
avaliación por parte de especialistas da área, chegamos, finalmente, a un conxunto de dezanove textos, que dan corpo ao número especial que agora presentamos.

Son vinte e sete os investigadores que se dispuxeron a contribuír con textos da súa autoría a esta publicación, provenientes de diversas rexións de Brasil e de Galicia - mais tamén de outros territorios, como Hungría e Estados Unidos -, marcando a presencia de case unha vintena de institucións nesta colectánea orientada á lingua e á literatura galegas, a saber: Secretaría Xeral de Política Lingüística, Consello da Cultura Galega, Instituto da Lingua Galega, Real Academia Galega, Universidade de Santiago de Compostela, Universidade Federal da Bahia, Universidade do Estado da Bahia, Universidade Federal do Amazonas, Universidade Federal de Goiás, Universidade Federal de Mato Grosso do Sul, Universidade Federal do Paraná, Universidade Federal do Rio de Janeiro, Universidade Federal Fluminense, Universidade do Estado do Rio de Janeiro, Universidade Federal da Fronteira Sul, Universidade Federal de Minas Gerais, Eötvös Loránd Tudományegyetem, The University of Colorado Boulder.

Ademais dos autores dos artigos, outros investigadores que contribuiron enormemente para a construcción deste número especial foron os trinta e catro especialistas que avaliaron criteriosamente cada unha das contribucións do volume, oriundos dalgunha das universidades xa mencionadas ou doutras, de Galicia, Brasil, Portugal e Estados Unidos: Universidade da Coruña, Universidade de Vigo, Universidade do Minho, The University of Iowa, Universidade Estadual de Feira de Santana, Universidade Federal de Alagoas, Universidade Federal Rural de Pernambuco, Universidade Federal do Pará, Universidade Federal do Espírito Santo, Universidade Federal do Pampa, Universidade Estadual de Londrina, Universidade de Brasília.

O número expresivo de artigos, de autores e das diversas institucións partícipes desta publicación, así como a calidade deses mesmos textos, 
demostran, per se, a vitalidade e a robustez dos estudos orientados á lingua e á literatura galegas na actualidade, desenvolvidos en Galicia, en Brasil ou noutros dominios. Son, deste modo, mostras interesantes de todo o importante labor que se desenvolveu nestes últimos anos no campo da lingüística e da teoría/análise literarias de natureza galeguista.

Abre o camiño Valentín García Gómez, Secretario xeral de Política Lingüística da Xunta de Galicia, aproximándonos á actualidade dos estudos galegos no ámbito internacional. Na contribución preséntanse a rede de lectorados e de centros de estudos galegos, as oportunidades de aprendizaxe do galego para estranxeiros e as posibilidades de estadías orientadas á investigación dentro do territorio galego. O texto traza, ademais, un panorama da situación do idioma dentro da Unión Europea e das comunidades emigrantes galegas. Para finalizar, preséntanse algunhas das principais vías para o estreitamento das relacións de Galicia coa lusofonía.

Pola súa parte, Rosario Álvarez, presidenta do Consello da Cultura Galega, convídanos a camiñar por Galicia, Portugal e Brasil na procura dos nomes dados á Vía Láctea. Estas formas están acompañadas da motivación que lles deu orixe e dunha análise xeolingüística que analiza a relación co núcleo cultural de partida e a actualidade das mesmas.

Segue a achega de Ana Boullón, académica de número da Real Academia Galega, que nos leva a percorrer Galicia da man da toponimia galega máis frecuente para comprendermos os principais trazos físicos, urbanos e relixiosos que a conformaron historicamente. Desta forma, aproximámonos ao significado e ás diferentes formas destes topónimos que serán clasificados en áreas semánticas.

Co seu artigo, dedicado á memoria da Profa. Maria del Rosário Suárez Albán - fundadora do CELGA - , a tríade de investigadoras do proxecto Atlas Linguístico do Brasil (ALiB), Silvana Ribeiro, Jacyra Mota e Aparecida Isquerdo, establece un tránsito entre Galicia, Portugal e Brasil, ao analizar, con base en atlas 
lingüísticos e outros córpora, varias denominacións rexistradas en galego ou portugués (europeo e brasileiro) para “o xogo infantil en que un xogador, cos ollos tapados, intenta pillar algún dos participantes ou adiviñar quen é".

Seguindo polos camiños do léxico e da dialectoloxía, Daniela Claro, Silvana Ribeiro e Luis de Jesus, da Universidade Federal da Bahia, presentan un estudo comparativo de natureza diatópica e cuantitativa canto a termos presentes no volume V do Atlas Lingüístico Galego (ALGa), con relación aos seus usos na rede social Twitter, tendo como principal fin a análise da vitalidade dos vocábulos seleccionados na comunicación levada a cabo en tal rede social.

Tamén dedicándose ás palabras, Ildikó Szijj, da Eötvös Loránd Tudományegyetem (Budapest), traza unha ruta de estudo na cal describe o inventario de formacións compositivas do tipo verbo + sustantivo nun repertorio lexicográfico das linguas galega, portuguesa e española, examinando os casos de correspondencia ou diferenciación (formal ou semántica) entre o galego e as outras dúas linguas con respecto a palabras xeradas con base neste esquema formativo.

Aínda nos interesantes camiños das palabras, Arivaldo de Souza, da Universidade Federal da Bahia, analiza no seu artigo a voz puto na cantiga de escarnio e maldicir Eu digo mal com'ome fodimalho, do trobador Pero da Ponte, rastrexando a rica polisemia e a mudanza semántica atinentes a este vocábulo na historia da lingua.

Con Francisco Calvo del Olmo e Sweder Souza, ambos da Universidade Federal do Paraná, viaxamos até a rexión Sur do Brasil para coñecermos a actualidade dos estudos galegos nos cursos de Letras da Universidade Federal do Paraná. Os autores preséntannos o contexto de creación e a materia optativa Introdução à Língua e à Cultura Galegas e analizan a través de cuestionarios a familiarización dos discentes cos estudos galegos antes e despois de cursar a disciplina. 
Tamén dende o contexto educativo, Daniel Amarelo, da The University of Colorado - Boulder, lévanos até as aulas de ensino secundario galegas. Partindo dos fundamentos da pedagoxía queer, da lingüística e da didáctica de linguas, Amarelo realiza a modo de ensaio unha explicación e xustificación do porqué traballarmos cunha perspectiva máis orientada á interrogación do que á resposta fechada. Para iso propón actividades que poderían ser levadas ás aulas de galego e portugués.

Pola súa parte, Lucía Sande, da Universidade do Estado do Rio de Janeiro, convídanos a irmos até a Idade Media da man das soldadeiras. A autora analiza o corpus das cantigas de escarnio galego-portuguesas para identificar cales son as representacións desas mulleres que aparecen no mesmo.

Aínda no medievo, Guilherme Antunes Junior, da Universidade Federal do Rio de Janeiro, aproxímanos á colección de milagres das Cantigas de Santa Maria. A súa análise ten como obxecto as miniaturas e os rótulos correspondentes en tres desas cantigas, na busca das incoherencias entre ambas partes, a imaxética e a textual.

Xa Lúcia Leiro, da Universidade do Estado da Bahia, sitúa o seu texto no medio do Atlántico, na ruta migratoria que une Galicia e Bahia. A autora analiza as cartas de Cándido Leiro Duran a seu pai, tendo como base para a súa investigación os conceptos de egodocumento, modalidade discursiva, egosepecularidade e ancestralidade discursiva.

Participan deste camiño aberto entre Galicia e Bahia Antón Corbacho e Margareth de Lourdes Nunes, da Universidade Federal de Goiás, estudando a novela Vida, Paixão e Morte Republicana de Don Ramón Fernández y Fernández, de Nélson de Araújo. Examínase así a caracterización dos personaxes galegos na novela e preténdese explicar as razóns polas cales a obra non tivo éxito entre a diáspora galega soteropolitana.

Pola súa parte, a contribución de Bárbara Monteiro e Pedro Uzêda - da Universidade do Estado do Rio de Janeiro e da Universidade Federal da Bahia, 
respectivamente - propón tamén unha travesía, da man de Rosalía de Castro, achegándose á influencia da autora na migración americana e ás figuras femininas da obra rosaliana neste contexto.

Seguindo ese percorrido que vai de Brasil a Galicia, Thayane Gaspar, da Universidade Federal do Rio de Janeiro, achégase á representación de Brasil na literatura galega a través da obra de Neira Vilas. O texto apóiase nas principais investigacións sobre a diáspora galega e na teoría das representacións sociais e da análise do discurso.

Xa Fernando Gebra, da Universidade Federal da Fronteira Sul, traza un camiño entre Portugal e Galicia seguindo a obra de Alfredo Guisado. Tres son os focos principais da análise que realiza o investigador: o repertorio ruralpanteísta, a participación na publicación El Tea e as aproximacións de Alfredo Guisado aos artistas galegos.

No ámbito da narrativa, Fernanda Lacombe, da Universidade Federal Fluminense, propón unha lectura da escena que se desenvolve no xardín dos Andrade no libro A Esmorga, de Eduardo Blanco-Amor. Para a interpretación do capítulo a autora mobiliza os conceptos de corpos impropios e da homosexualidade marxinal.

Seguindo a vía do estudo da poesía galega, Marcelo de Mello, da Universidade Federal de Minas Gerais, lévanos até a obra Poesía última de amor e enfermidade, de Lois Pereiro. O autor discute a relación entre escrita e visualidade no poemario, examinando a organización do mesmo e a intertextualidade interna.

Por último, Leilson de Souza Filho e Saturnino Valladares, ambos da Universidade Federal do Amazonas, estudan o erotismo presente na primeira parte da obra Unha tempada no paraíso, do escritor Claudio Rodríguez Fer. Os autores seleccionan principalmente aqueles poemas nos que están máis presentes o erotismo, o compromiso social e a utopía libertaria. 
Como coorganizadores deste número especial, agradecemos a boa acollida da proposta dende a organización da revista - a cargo dos Profs. Juliana Gayer e Felipe Kupske- e a inestimábel implicación por parte dos autores e dos avaliadores. Lanzamos así esta contribución co desexo de alentar ás e aos investigadores dos estudos galegos a seguir facendo do CELGA un espazo de encontro e creación dende a Bahia. Ademais, a través destes textos unímonos colectivamente e dende o eido académico ás celebracións que veñen conmemorando o ano Xacobeo nestes anos de 2021-2022. A alegría é dobre ao festexarmos tamén os primeiros vinte e cinco anos de camiñada do noso centro, para que sirvan como faro para os próximos vinte e cinco. Este número especial quere ser igualmente un brinde de lembranza e homenaxe a aqueles académicos que ao longo desta andaina cultivaron e estimularon o crecemento desta casa.

A todos, unha moi proveitosa lectura. 